\title{
Sex Differences in Neurocognitive Function in Adults with HIV: Patterns, Predictors, and Mechanisms
}

\author{
Leah H. Rubin $^{1,2} \cdot$ Gretchen N. Neigh $^{3}$ - Erin E. Sundermann ${ }^{4} \cdot$ Yanxun Xu $^{5,6} \cdot$ Eileen P. Scully $^{7} \cdot$ Pauline M. Maki $^{8,9}$
}

Published online: 14 September 2019

(C) Springer Science+Business Media, LLC, part of Springer Nature 2019

\begin{abstract}
Purpose of Review Sex differences in cognitive function are well documented yet few studies had adequate numbers of women and men living with HIV (WLWH; MLWH) to identify sex differences in neurocognitive impairment (NCI) and the factors contributing to NCI. Here, we review evidence that WLWH may be at greater risk for NCI.

Recent Findings We conducted a systematic review of recent studies of NCI in WLWH versus MLWH. A power analysis showed that few HIV studies have sufficient power to address male/female differences in NCI but studies with adequate power find evidence of greater NCI in WLWH, particularly in the domains of memory, speed of information processing, and motor function. Summary Sex is an important determinant of NCI in HIV, and may relate to male/female differences in cognitive reserve, comorbidities (mental health and substance use disorders), and biological factors (e.g., inflammation, hormonal, genetic).
\end{abstract}

Keywords Sex differences $\cdot$ Cognition $\cdot$ Neurocognition $\cdot$ HIV

\section{Introduction}

With the National Institutes of Health (NIH) mandate to consider sex as a biological variable [1], there is growing appreciation and recognition of sex differences in brain function and brain disorders [2]. Historically, very few studies included adequate numbers of women to sufficiently address key

This article is part of the Topical Collection on Sex and Gender Issues in Behavioral Health

Electronic supplementary material The online version of this article (https://doi.org/10.1007/s11920-019-1089-x) contains supplementary material, which is available to authorized users.

Leah H. Rubin

lrubin1@jhmi.edu

1 Department of Neurology and Psychiatry, Johns Hopkins University School of Medicine, 600 N. Wolfe St., Meyer 6-133a, Baltimore, MD 21287-7613, USA

2 Department of Epidemiology, Johns Hopkins School of Public Health, Baltimore, MD, USA

3 Department of Anatomy and Neurobiology, School of Medicine, Virginia Commonwealth University, Richmond, VA, USA

4 School of Medicine, University of California San Diego, La Jolla, CA, USA questions about possible sex differences in neurocognitive complications of HIV. From 1988 to 1997, females comprised only $9.3 \%$ of research participants in studies of HIV and cognition [3]. Since the introduction of effective antiretroviral therapy (ART), more neurocognitive studies focused on women living with HIV (WLWH), but sample sizes have remained modest [4-11]. The Women's Interagency HIV Study (WIHS)
Department of Applied Mathematics and Statistics, Johns Hopkins University, Baltimore, MD, USA

6 Division of Biostatistics and Bioinformatics at The Sidney Kimmel Comprehensive Cancer Center, Johns Hopkins University School of Medicine, Baltimore, MD, USA

7 Division of Infectious Diseases, Department of Medicine, Johns Hopkins School of Medicine, Baltimore, MD, USA

8 Department of Psychiatry, University of Illinois at Chicago, Chicago, IL, USA

9 Department of Psychology, University of Illinois at Chicago, Chicago, IL, USA 
is the largest prospective cohort study in WLWH in the United States and has made fundamental contributions to understanding about neurocognitive function in WLWH. The WIHS neurocognitive studies have several strengths including a longitudinal design, a large sample (>1500), a well-matched group of HIV-seronegative (HIV-) women [12, 13], and extensive comorbidity data (e.g., cardiovascular, mental health). Through its merge with the Multicenter AIDS Cohort Study (MACS) as the MACS/WIHS Combined Cohort Study (MWCCS), there is also now access to a well-matched group of men living with HIV (MLWH) and HIV- men [14••, 15].

Compared to MLWH, WLWH may be at greater risk for neurocognitive impairment (NCI) due in part to a disproportionate burden of poverty, low literacy levels, low educational attainment, substance abuse, poor mental health, barriers to health care services, and environmental exposures prevalent in predominantly minority urban communities $[11,13,14 \bullet \bullet]$. There is also evidence to suggest that WLWH may be more cognitively susceptible than MLWH to the effects of the same challenges [15]. In addition, biological factors such as sex steroid hormones (e.g., estrogen, progesterone, testosterone) and female-specific hormonal milieus (e.g., pregnancy, menstrual cycle, menopause transition) may contribute to sex differences in the pattern and magnitude of HIV-associated alterations in neurocognitive function. The goal of this review is to provide a systematic review of sex differences in the prevalence and patterns of neurocognitive function in HIV, identify key gaps in knowledge, and discuss some of the potential biological drivers.

\section{Literature Search}

To identify peer-reviewed studies on sex differences in the prevalence and patterns of neurocognitive function in people living with HIV (PLWH), we searched PubMED (May 2019) for titles/abstracts containing MeSH terms "sex," or "gender" combined with "cognition," "cognitive," "HIV-associated Neurocognitive Disorders (HAND)," "neurocognitive," "neurocognition," or "neuropsych," combined with "HIV," or "HIV-infected" with additional limits of "English Language," "Humans," and published in the last 5 years (2013 and after) per article instructions. Our search yielded 307 abstracts which were reviewed for the following inclusion criteria: (1) HIV sample size $\geq 100$, (2) neurocognitive function determined based on two or more validated neuropsychological tests, and (3) prevalence or pattern of neurocognitive function by sex. Six articles met criteria. Five additional pub-

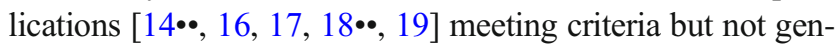
erated by this search were also included, for a total of 11 publications (Table 1). Two of the eleven publications reflect different analyses (one cross-sectional, one on a longitudinal subset) from the same cohort (CNS HIV Anti-Retroviral therapy Effects Research-CHARTER) [18, 19] and both papers were included.

\section{Characteristics of Included Studies and Study Participants}

Of the eleven articles, nine produced cross-sectional results and two longitudinal results. Sample sizes ranged from 137 to 1361 (median $=266$ ) for a total of 4456 PLWH. Six studies (54\%) included HIV- controls in sample sizes ranging from 58 to 710 (median $=300$ ), for a total of 2143 HIV- individuals. The percent of WLWH ranged from 15 to $62 \%$ (median $=43 \%)$ and HIV - females from 30 to $65 \%$ (median $=$ $55 \%$ ). The average age of participants was 40 years. Overall $58 \%$ of PLWH had undetectable HIV RNA (median $=62 \%$ ). The articles spanned eight different countries, with $27 \%$ based in the US.

Of the eleven articles, two [16, 25] used raw neuropsychological test scores, three $[14 \bullet \bullet, 21,24]$ transformed raw scores into demographically adjusted (age, education, sex, race/ethnicity) T-scores based on the HIV- individuals from the same cohort, and six [17, 18••, 19, 20, 22, 23] transformed raw scores into demographically adjusted T-scores based on an external normative sample of HIV- individuals.

\section{Findings Related to Sex Differences in Global Cognitive Function}

Of the nine cross-sectional analyses, seven [17, 18••, 20-24] examined sex differences on a global neurocognitive measure in PLWH (Table 1). In unadjusted analyses, three [17, 18••, 24] of seven [20-23] analyses (43\%) demonstrated that the prevalence of NCI was higher in WLWH. In the first of those three studies, global NCI (defined as a global deficit scores [GDS] score of at least 0.50 ) was found in $52 \%$ of WLWH versus only $41 \%$ of MLWH, for an $11 \%$ difference and an odds ratio (OR) of 1.53 (95\% confidence interval [CI] 1.13$2.06, P=0.005)[18 \bullet \bullet$. No sex difference was observed among the HIV - individuals $($ women $=27 \%$ vs. men $=$ $26 \%$ ). In the second study, the prevalence of NCI plus functional impairment (mild neurocognitive disorder + HAD) was $30 \%$ in WLWH versus $19 \%$ in MLWH, again for an $11 \%$ difference $(\mathrm{OR}=1.79,95 \%$ CI $1.10-2.87, P=0.02)$ [17]. That study did not include a HIV-control group. In the third study, WLWH had a significantly lower GDS score (mean $[M]=0.38$; standard deviation $[\mathrm{SD}]=0.35)$ than $\mathrm{MLWH}$ $(M=0.27, \mathrm{SD}=0.30)(P=0.04)$ [24]. Additionally, the mean sex difference in PLWH was greater than the mean difference in HIV - individuals. In adjusted analyses across seven analyses, the sex differences remained significant in three studies $[18 \bullet \bullet, 22,24]$, were attenuated in two $[17,20]$ with one just missing significance after adjusting for disease characteristics particularly current CD4 count $(P=0.08)$ [20], and were no 


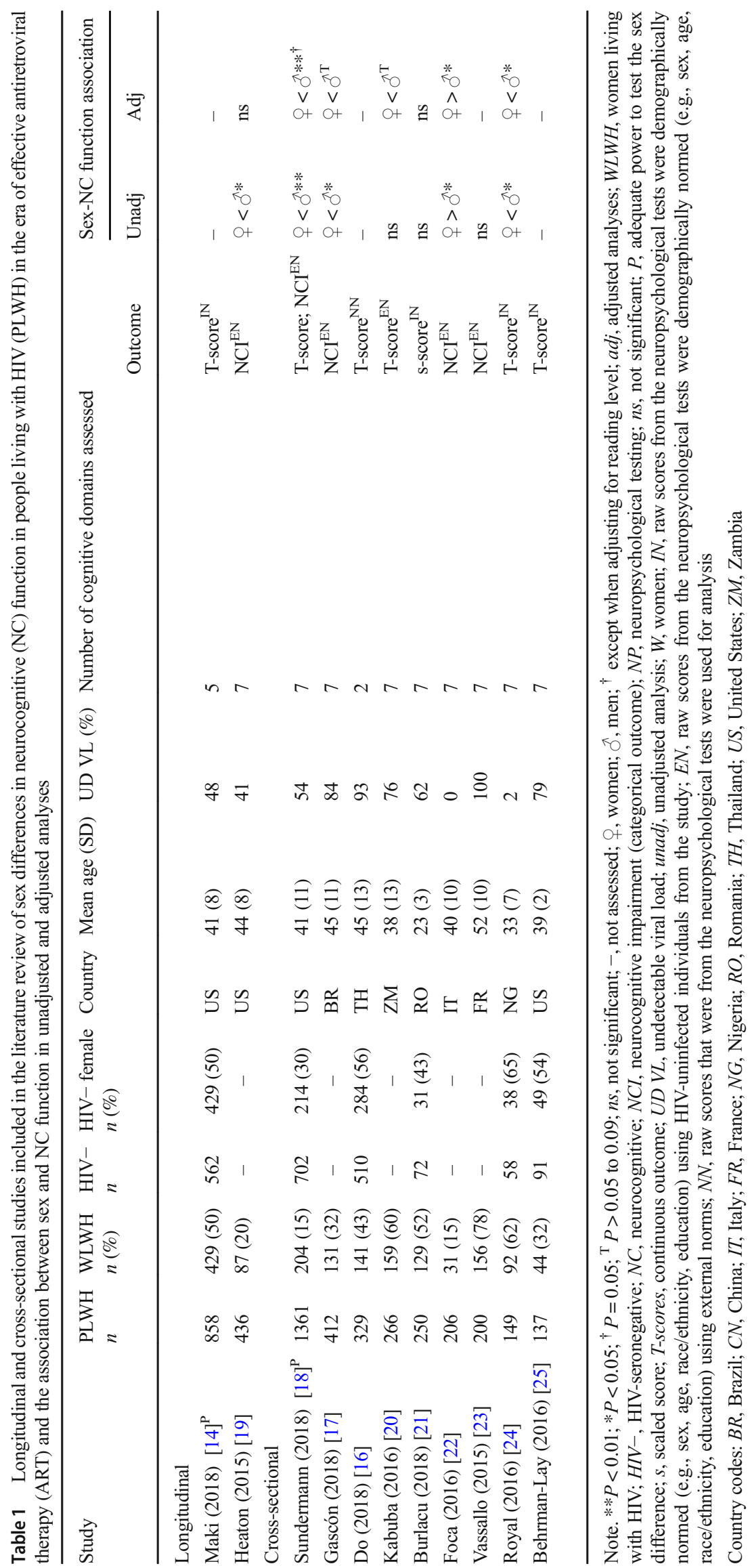


longer significant in three analyses $[20,21,23]$. Of the three analyses in which the sex differences remained significant $[18 \bullet \bullet, 22,24]$, one demonstrated that WLWH were less likely to have HAND (29\%) then MLWH (50\%); however, this study only had 31 WLWH [22].

Only one longitudinal study [19] to date has examined the risk of decline on a global measure of neurocognitive function between WLWH and MLWH. In univariate analyses, WLWH showed a $76 \%$ increased risk of decline over a 35-month follow-up versus MLWH $(\mathrm{OR}=1.76, P=$ 0.01 ); however, sex no longer remained a significant predictor of risk of decline in the final multivariable model. This model controlled for demographic (years of education), disease, laboratory, treatment, and mental health factors (lifetime major depressive disorder [MDD] and substance use disorders).

\section{Findings Related to Sex Differences in Specific Cognitive Domains}

Across the eleven studies, six [16, 18••, 20, 21, 24, 25] crosssectional and one [14*0] longitudinal analysis examined sex differences in domain-specific cognitive performance in PLWH (Table 2). For learning and memory, two [20, 24] of five $[18 \bullet \cdot, 21,25]$ analyses $(40 \%)$ demonstrated that WLWH were more likely have lower performance scores or greater impairment than MLWH. Only Royal et al. [24] included HIV- men and women as comparators. For speed of information processing (SIP), two [14••, 16] of seven [18••, 20, 21, 24, 25] analyses (28\%) demonstrated that WLWH were more likely to perform lower or show higher impairment than MLWH. For motor skills, two [14••, 21] of seven [16, 18••, $20,24,25]$ analyses $(28 \%)$ demonstrated that WLWH performed lower than MLWH. Among seven studies examining executive function $[14 \bullet \cdot 16,18,20,21,24,25]$, only one [14••] analysis (14\%) demonstrated that WLWH performed lower than MLWH. However, this pattern was only noted on a measure of mental flexibility and not behavioral inhibition $[14 \bullet \cdot]$. No sex differences were evident for fluency $[16,18 \bullet \bullet$, $20,21,24,25]$ or attention/working memory $[16,18,20,21$, $24,25]$. The largest longitudinal study to date found that females performed worse on SIP and motor function, and that the magnitude of this sex differences did not change over time [14••]. Learning, memory, fluency, and the attention/working memory domains were not assessed [140*] and thus additional research is needed to determine if these other domains remain stable in HIV over time.

To determine the rigor and reproducibility of the eleven analyses, we ran a series of power analysis using both the Tscore (continuous) and NCI (categorical). Figure 1 shows the power versus effect size (T-score difference) for different sample sizes when the sample size for men and women is (A) equal (50/50), (B) 60/40, (C) 70/30, and (D) 80/20. As the

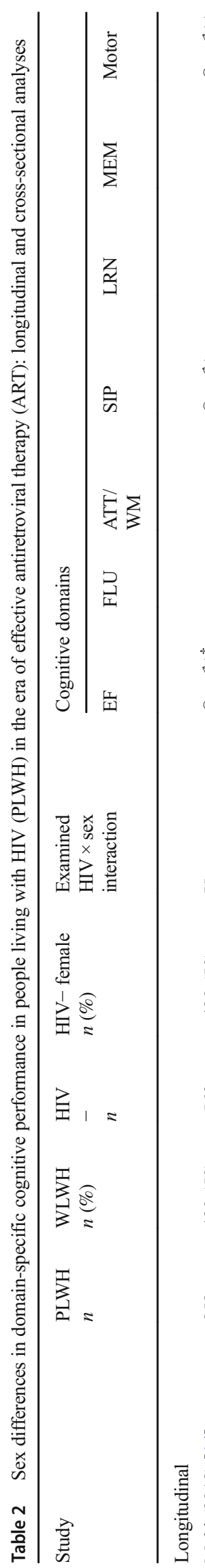

菜 $V$
O

\section{主}

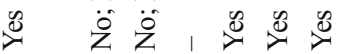

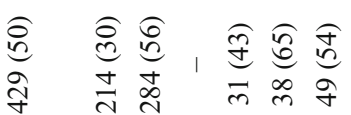

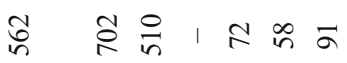

क्षे

每

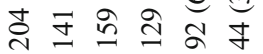

क

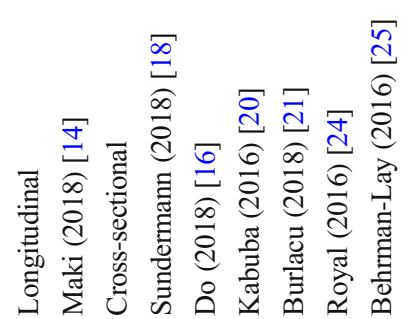


(a) T-score: $50 \% / g r o u p$

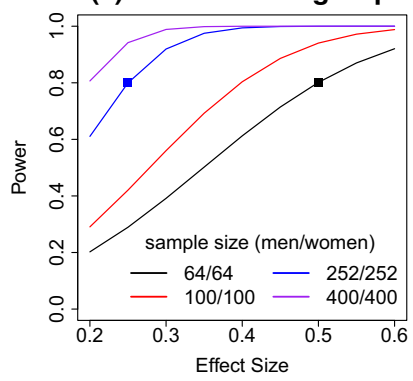

(b) T-score: $60 / 40 \%$

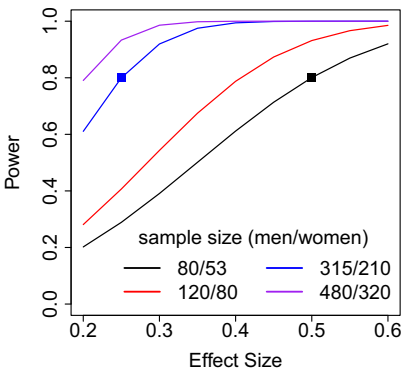

(c) T-score: $70 / 30 \%$

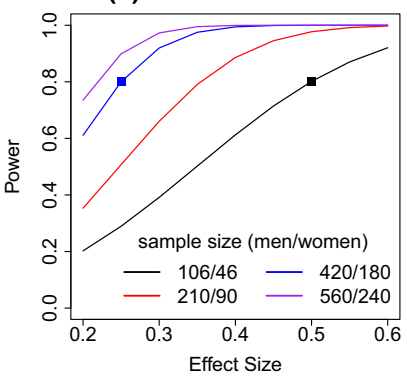

(g) $\mathrm{NCl}: 70 / 30 \%$

(e) $\mathrm{NCl}: 50 \% / g r o u p$

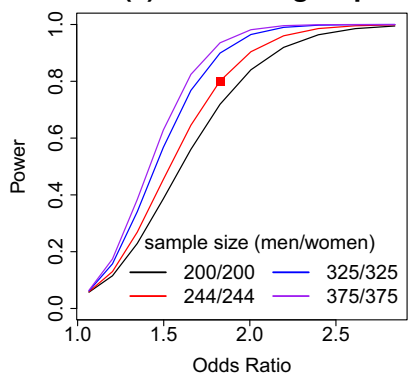

(f) $\mathrm{NCl}: 60 / 40 \%$

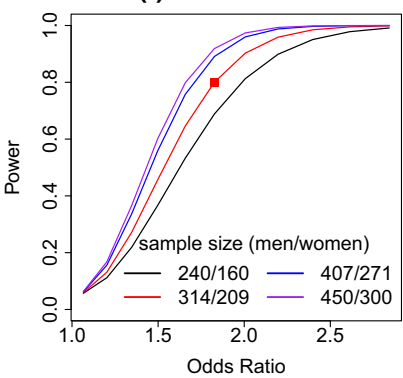

$\mathrm{NCl}$ in MLWH is $41 \%$ and $52 \%$ in WLWH:

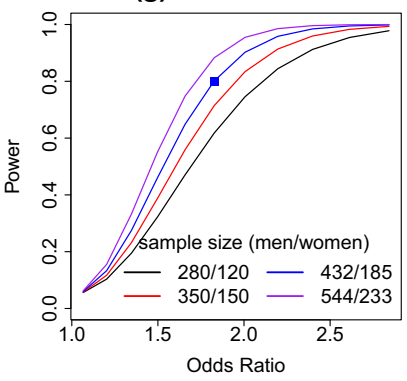

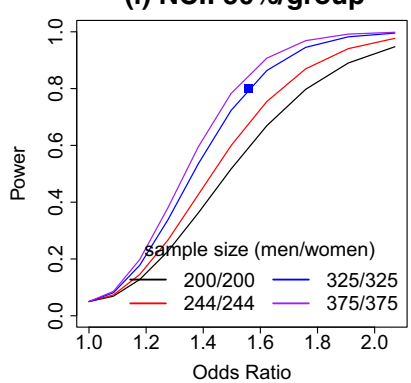

(j) $\mathrm{NCl}: 60 / 40 \%$

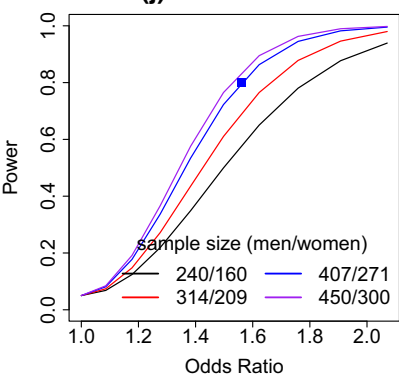

Fig. 1 Power simulations computed to determine the sample size needed/ group to have $80 \%$ power to detect sex differences in T-scores (continuous) and neurocognitive impairment (NCI; categorical) in HIV. For T-scores, power versus effect size is plotted for different sample sizes $(n)$ when the proportion of men and women living with HIV is a equal (50\%/group), b 60/40, c 70/30, and d 80/20. For NCI, power versus odds

(d) T-score: $80 / 20 \%$

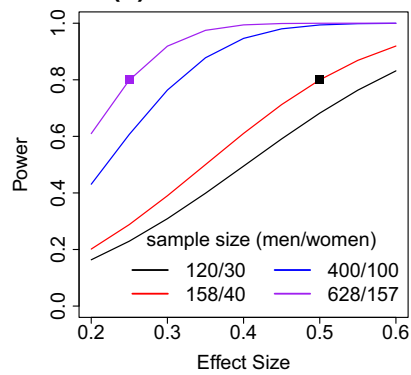

(h) NCl: $\mathbf{8 0 / 2 0 \%}$

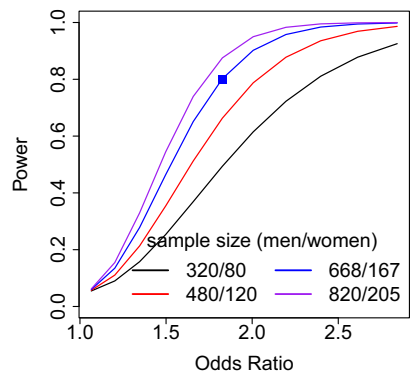

(k) $\mathrm{NCl}: \mathbf{7 0 / 3 0 \%}$

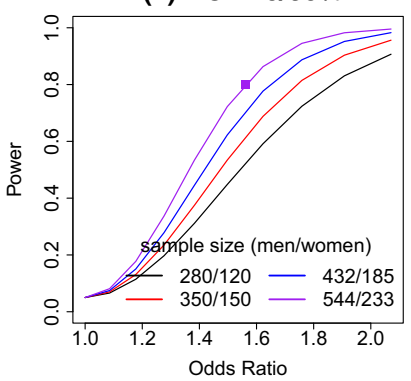

(I) $\mathrm{NCl}: \mathbf{8 0 / 2 0 \%}$

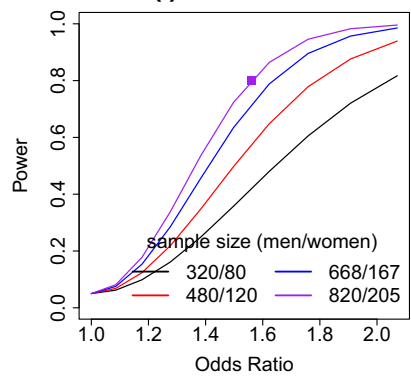

ratio is plotted for different sample sizes when we assume $19 \% \mathrm{NCI}$ in MLWH and 30\% in WLWH and when the proportion of HIV-seropositive men and women is e equal, f 60/40, g 70/30, and $\mathbf{h} 80 / 20$ women. Power versus odds ratio is plotted for different sample sizes when we assume $41 \%$ NCI in MLWH and 52\% in WLWH and when the proportion of HIV-seropositive men and women is i equal, $\mathbf{j} 60 / 40, \mathbf{k} 70 / 30$, and $\mathbf{l} 80 / 20$ proportion of MLWH and women in the sample diverge, larger sample sizes are needed to have adequate (e.g., $80 \%$ power). For example, to detect a T-score difference of $0.25 \mathrm{SD}$ when the number of men and women are equal, a sample of 504 ( $n=252$ /group) is needed whereas a sample of 525 is needed when the split is $60 / 40$ (315 men; 210 women), 600 when the split is $70 / 30$ ( 420 men, 180 women), and 785 when the split is $80 / 20$ (628 men, 157 women). Of the studies ex-

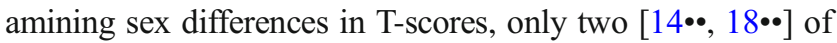
seven studies [16, 20, 21, 24, 25] were adequately powered; it is notable that these two studies had divergent findings, one with sex differences and one without.
We also examined the sample sizes needed to detect a significant increased odds (odds ratio) of NCI in WLWH than MLWH, using prevalence rates from studies reviewed above $[17,18]$. Figure 1 panels $E-G$ show the sample size needed to detect a significant odds ratio with sufficient power when NCI is set at 30\% for WLWH and 19\% for MLWH [17] and the sample size for men and women is (E) equal (50/50), (F) 60/ 40, (G) 70/30, and (G) 80/20. Figure 1 panels $\mathrm{H}-\mathrm{L}$ show the sample size needed to detect a significant odds ratio with sufficient power when NCI is set at $52 \%$ for WLWH and $41 \%$ for MLWH where even larger sample sizes are needed (50/50 split; $N=650: 325$ per group; $80 / 20$ split; $N=1025$ : 
820 men, 205 women). Of the studies examining sex differences with a categorical outcome (e.g., NCI, HAND), only one [18••] of seven studies [17, 19, 22-25] was adequately powered.

While powering for the sex difference in PLWH is pertinent, the optimal study design is to examine sex differences by HIV-serostatus on a T-score or NCI; this allows analysis of the sex by HIV infection interaction. We conducted a series of power simulations to determine the sample sizes needed per cell to have $80 \%$ power to detect an interaction effect size of 0.25 when we vary the proportion of men and women (50/50, $60 / 40,70 / 30,80 / 20)$ and the proportion of PLWH $(66 \%$ or $75 \%$ ) (Supplemental Materials). Of the studies examining an HIV-serostatus by sex interaction, only one [14.•] of four [21, $24,25]$ studies was adequately powered. For NCI, we also conducted a series of simulations to determine power needed to detect a significant odds ratio (Supplemental Materials). Only one [18••] of the two studies [24] was adequately powered.

In sum, although a number of recent studies have examined sex differences in neurocognitive function, few studies are adequately powered to detect a meaningful sex difference. The lack of statistical power appears to be an important consideration and likely contributes to inconsistent findings of sex differences in NCI. The strongest available evidence indicates a higher prevalence of NCI in WLWH compared to MLWH, with the largest differences in memory and learning followed by SIP and motor, and inconsistent findings in executive function. Adequately powered studies are needed to determine the reproducibility and longitudinal course of these findings. Adjusting for critical factors such as reading ability, education, mental health, and poverty reduces the magnitude of the sex difference, and elucidates factors that contribute to NCI in women. Given that neuropsychological testing in clinical practice adjusts for age and educational differences but not mental health and other factors, a higher prevalence of NCI in women in the clinical setting may be expected, and the consequent need for interventions may be higher in women.

\section{Why Are There Sex Differences in the Prevalence and Patterns of Neurocognitive Function in HIV?}

\section{Sex Differences in Cognitive Reserve}

A greater likelihood of NCI among WLWH versus MLWH may reflect differences in psychological risk factors (e.g., poverty, low education, substance use, depression, early life trauma, barriers to healthcare) which are more common in women versus men $[26,27]$. These factors can additively or synergistically lower cognitive reserve before HIV infection and contribute to greater cognitive dysfunction following infection $[28,29]$. Cognitive reserve is a key determinant of NCI because it sets a threshold level of brain insult that is necessary for NCI to manifest [30, 31]. Applied to HIV, women with low cognitive reserve would be less able to compensate for the myriad adverse neurobiological effects of HIV and, thus, would be more susceptible to NCI than those with high cognitive reserve. Accordingly, the higher rates of neurocognitive risk factors in WLWH versus MLWH and the resulting lower cognitive reserve may contribute to women's increased susceptibility to NCI.

Reading level, as assessed by word pronunciation tests such as the Wide Range Achievement Test (WRAT) and the North American Reading Test (NART), is a common proxy for cognitive reserve. Reading level is thought to better reflect educational attainment than years of education especially in lower socioeconomic, ethnically diverse populations due to factors that limit the effectiveness of schools serving these populations including less access to quality education, reading materials and school supplies, and teaching expertise [32]. Consistent with this notion, low reading level, but not low education $(<12$ years), was a risk factor for neurocognitive decline in HIV cohort studies [13, 32]. Low reading level is also associated with a range of clinical outcomes including hospitalizations and outpatient doctor visits [33], and therefore could also indirectly influence neurocognitive performance through factors such as low health literacy, increased medical comorbidities, and medication non-adherence.

In the WIHS, reading level, years of education, income, and race were more strongly associated with neurocognitive performance than HIV-serostatus [13], indicating that adverse sociodemographic factors are key determinants of neurocognitive function in WLWH. An HIV Neurobehavioral Research Program (HNRP) study addressed whether the higher rates of psychosocial risk factors in WLWH account for their higher rates of NCI versus MLWH $[18 \cdot \bullet]$ and for any sex differences in association between HIVserostatus and NCI. NCI was more prevalent in WLWH versus MLWH, but not after adjustment for the lower reading level in WLWH. HIV-seropositivity was more strongly associated with NCI in women versus men and this association was attenuated but not eliminated after adjustment for reading level. Those results were driven by non-Hispanic Blacks [18••]. The greater prevalence of NCI in WLWH may therefore be due in part to their suboptimal educational experience, which may lower cognitive reserve and increase susceptibility to NCI. Further, study samples that are predominantly White and more educated may be less likely to yield a sex difference. It is notable that two studies in Africa did find evidence of worse NCI in WLWH compared to MLWH [20, 24].

\section{Sex Differences in Mental Health Risk Factors and Disorders}

Stress and early life trauma as well as mental health disorders including depression and post-traumatic stress disorder 
(PTSD) may contribute to higher rates of NCI in WLWH versus MLWH. Stigma and social isolation associated with the diagnosis of HIV may contribute to progression of NCI. Mental health risk factors and disorders are strongly associated with neurocognitive function in WLWH. In a series of cross-sectional WIHS studies, we examined associations between PTSD, anxiety, perceived stress, depression, and neurocognitive function. PTSD, anxiety, perceived stress, and depression were each associated with deficits in learning, memory, and attention [13, 34-36]. High stress and elevated anxiety were associated with decreased learning and memory only among WLWH $[35,36]$. In WLWH but not HIV- women, higher perceived stress and PTSD were associated with accelerated declines in fluency, learning, and memory [37]. Irrespective of time or HIV-serostatus, depression, perceived stress, and PTSD were associated with lower SIP, executive function, and global neurocognitive function. In a longitudinal study of South African WLWH, trauma exposure was related to less improvement in executive function and fluency [38].

Few large-scale HIV cohort studies assess sex differences in mental health risk factors and disorders on NCI. We examined the association of elevated depressive symptoms with $\mathrm{NCI}$ in the WIHS and MACS [15]. Although MLWH showed a higher frequency of elevated depressive symptoms than WLWH (perhaps due to sexual minority status), WLWH with elevated depressive symptoms had 5 times the odds of impairment in executive control/inhibition versus HIV- women with elevated depressive symptoms, and 3 times the odds of impairment on that measure versus MLWH with elevated depressive symptoms. Including comprehensive mental health measures particularly diagnostic measures in HIV cohort studies is warranted to better understand how mental health and sex differences in mental health contribute to HIV-associated NCI.

\section{Sex Differences in Sex Steroid Hormones and Hormonal Milieus}

Sex steroids, particularly estradiol, progesterone and testosterone, influence cognition in healthy individuals, contributing, for example, to sex differences in performance on verbal tasks (favoring females) and visuospatial tasks (favoring males). For women, changes in sex steroid hormones across the menstrual cycle, pregnancy, and the menopause contribute to changes in neurocognitive performance [39]. In HIV, sex has an influence on pretreatment viral load [40], the immune response to HIV itself [41], and on measures of viral persistence and immune activation during effective ART [42•, 43•]. Estradiol has been directly linked to HIV transcriptional activity $[44,45]$ and may further influence neurocognitive function through effects on viral suppression and replication. Both estradiol and progesterone also have immunomodulatory effects, impacting cytokines and chemokine levels [46], contributing to sex differences in immune function. The role of peripheral aromatization of testosterone to estradiol is understudied in relation to NCI in PLWH. In WLWH, there is initial evidence of an association between testosterone insufficiency and cognitive complaints [47]. The cognitive effects of testosterone deficiency in MLWH are unclear [48, 49]. As sex steroids have both direct effects on neurocognitive indices and can also modulate HIV viral activity, the contribution of sex steroids and relative deficiencies to changes in neurocognitive function in MLWH and WLWH warrants further investigation.

\section{Sex Differences in Immune Function}

Immune responses are modulated by biological sex with implications for infectious, inflammatory, and autoimmune diseases $[50,51]$. Recent work highlighted the critical influence of sex on the immune system and the potential for sex-specific genetic determinants of immune function [52]. Early in the HIV epidemic, a sex difference in HIV viral load was identified, and importantly, despite lower viral loads in women, they were not protected against disease progression and CD4 decline. This sex difference had direct implications for treatment guidelines which were at the time based on viral load [40, 53, 54]. Sex differences in the immune response to HIV infection $[41,55]$ are likely contributors to these variations in pathogenesis. Chronic immune activation and inflammation predict HIV disease progression and mortality independent of viral load [56-61] and can trigger HIV-induced neurotoxicity and other comorbid diseases [62, 63].

A growing body of research demonstrates the importance of considering sex differences in monocyte-driven inflammatory biomarkers in PLWH. For example, sCD163 concentrations are higher in ART-naive WLWH versus ART-naive MLWH, both before and after 24 months of suppressive ART [64]. We found similar results in the WIHS and MACS (see analyses below). These differences may increase with aging. In a study of WLWH and MLWH with viremic control, sCD163 levels increased more with age among women versus men [65] (see also [66]). Other work indicates that WLWH show less of a decrease in SCD14 levels after cART initiation versus MLWH [56]. Hormonal factors appear to relate to sCD163 levels as women with lower ovarian reserve as measured by antimullerian hormone levels have higher sCD163 levels, independent of age [67]. Sex differences in monocytedriven inflammatory biomarkers in HIV have been studied in relation to cardiovascular disease $[65,67]$.

We examined sex differences in markers of monocyte activation and inflammation in 778 WIHS (74\% PLWH) and 503 MACS participants (65\% PLWH) [68]. In unadjusted analyses, PLWH versus HIV- individuals had higher levels of the monocyte-driven inflammatory markers sCD163 and sCD14 ( $P$ 's $<0.05$; Fig. 2). Females had higher sCD163 levels than 
Fig. 2 Male/female differences in monocyte-associated inflammatory markers and less specific markers of inflammation among people living with and without HIV. HIV+, HIVseropositive; HIV-, HIVseronegative

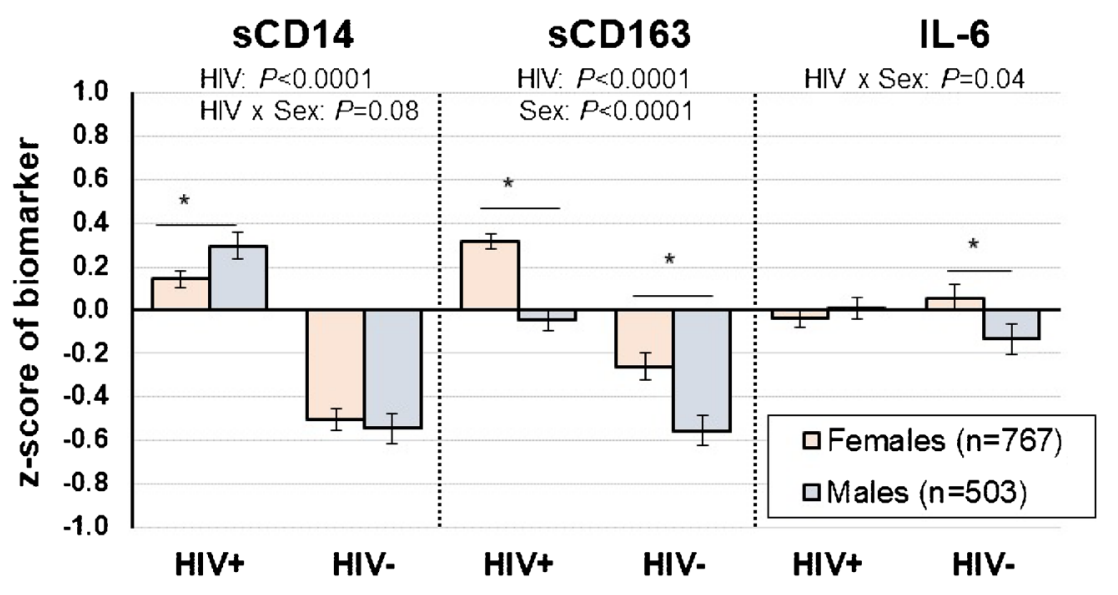

and atrophy in the hippocampus and dendritic shortening and atrophy in the prefrontal cortex [78-80]. The HPA axis response is initiated by release of corticotrophin releasing hormone $(\mathrm{CRH})$ from the hypothalamus which stimulates release of adrenocorticotrophic hormone (ACTH) from the pituitary that subsequently triggers production of cortisol by the adrenal glands. The impact of CRH on neurocognitive function is highlighted by a recent finding that single nucleotide polymorphisms (SNPs) in CRH receptor 1 or the gene that encodes the $\mathrm{CRH}$ binding protein associates with NCI in WLWH. The SNP in CRH receptor 1 also moderated the association of childhood trauma and NCI [81].

The HPA axis may play an important role in NCI in PLWH given that the HPA axis may be perturbed in HIV [82-85]. In many but not all $[86,87]$ studies, PLWH versus HIV- individuals show elevated basal cortisol levels [88-92], increased cortisol over time [93], attenuated cortisol responsivity to behavioral [94] and CRH challenges [91], and alterations in the diurnal rhythm of cortisol secretion [95]. The relevance of those findings to WLWH may be limited as they are based primarily on small studies of men that predate effective ART. There are sex differences in HPA axis activity $[96,97]$ and neurocognitive function (e.g., memory) vulnerabilities to cortisol [98, 99]. Our recent work highlights a potential causal relationship between cortisol and neurocognitive function in HIV that differs by sex. In a double-blind, placebo-controlled, cross-over study, a single dose of hydrocortisone (10 mg) improved learning and memory $4 \mathrm{~h}$ following treatment in WLWH [100] but not in MLWH [101].

Sex differences in neurocognitive function may also be in part driven by the interplay between the HPA axis function and the immune system at the level of the glucocorticoid receptor. The immune response to an acute laboratory stressor, a threat of shock stressor, was altered in PLWH such that TNFalpha responsivity was blunted for both sexes but IL-1 $\beta$ and cortisol responsivity were blunted in WLWH only [102]. It is unclear whether such differences are adaptive or maladaptive. Evidence of alterations at the level of the glucocorticoid receptor was found in the WIHS, where HIV and depressive 
symptoms were independently associated with impaired glucocorticoid signaling [103]. How those alterations influence neurocognition is not yet elucidated but warrants further investigation.

\section{Conclusions}

Based on a systematic review of recent studies to assess whether WLWH are more cognitively vulnerable than MLWH, paired with a power analysis to guide the interpretation of existing studies, we found that few HIV studies are adequately powered to address male/female differences in the presence and pattern of NCI but that those with adequate power do find evidence of greater NCI in WLWH, particularly in the domains of memory, SIP, and motor function. Biological sex needs to be considered in neurocognitive studies in PLWH. Factors that may contribute to these sex differences include cognitive reserve, mental health and other comorbidities, and biological factors.

Acknowledgments Research reported in this publication was supported by the National Institute of Mental Health of the National Institutes of Health under Award Numbers R01MH113512 (Rubin) and P30MH075773 (Haughey, Rubin, Sacktor).

\section{Compliance with Ethical Standards}

Conflict of Interest The authors declare that they have no conflict of interest.

Human and Animal Rights and Informed Consent This article does not contain any studies with human or animal subjects performed by any of the authors.

\section{References}

Papers of particular interest, published recently, have been highlighted as:

- Of importance

•- Of major importance

1. Clayton JA, Collins FS. Policy: NIH to balance sex in cell and animal studies. Nature. 2014;509(7500):282-3.

2. Cahill L. Why sex matters for neuroscience. Nat Rev Neurosci. 2006;7(6):477-84.

3. Fox-Tierney RA, Ickovics JR, Cerreta CL, Ethier KA. Potential sex differences remain understudied: a case study of the inclusion of women in HIV/AIDS-related neuropsychological research. Rev Gen Psychol. 1999;3(1):44-54.

4. Durvasula RS, Miller EN, Myers HF, Wyatt GE. Predictors of neuropsychological performance in HIV positive women. J Clin Exp Neuropsychol. 2001;23(2):149-63.

5. Wojna V, Skolasky RL, Hechavarria R, Mayo R, Selnes O, McArthur JC, et al. Prevalence of human immunodeficiency virus-associated cognitive impairment in a group of Hispanic women at risk for neurological impairment. J Neuro-Oncol. 2006;12(5):356-64.

6. Cohen RA, Boland R, Paul R, Tashima KT, Schoenbaum EE, Celentano DD, et al. Neurocognitive performance enhanced by highly active antiretroviral therapy in HIV-infected women. Aids. 2001;15(3):341-5.

7. Mason KI, Campbell A, Hawkins P, Madhere S, Johnson K, Takushi-Chinen R. Neuropsychological functioning in HIVpositive African-American women with a history of drug use. J Natl Med Assoc. 1998;90(11):665-74.

8. Stern RA, Arruda JE, Somerville JA, Cohen RA, Boland RJ, Stein $\mathrm{MD}$, et al. Neurobehavioral functioning in asymptomatic HIV-1 infected women. J Int Neuropsychol Soc. 1998;4(2):172-8.

9. Richardson JL, Martin EM, Jimenez N, Danley K, Cohen M, Carson VL, et al. Neuropsychological functioning in a cohort of HIV infected women: importance of antiretroviral therapy. J Int Neuropsychol Soc. 2002;8(6):781-93.

10. Richardson JL, Nowicki M, Danley K, Martin EM, Cohen MH, Gonzalez R, et al. Neuropsychological functioning in a cohort of HIV- and hepatitis C virus-infected women. AIDS. 2005;19(15): 1659-67.

11. Maki PM, Martin-Thormeyer E. HIV, cognition and women. Neuropsychol Rev. 2009;19(2):204-14.

12. Rubin LH, Maki PM, Springer G, Benning L, Anastos K, Gustafson D, et al. Cognitive trajectories over 4 years among HIV-infected women with optimal viral suppression. Neurology. 2017;89(15):1594-603.

13. Maki PM, Rubin LH, Valcour V, Martin E, Crystal H, Young M, et al. Cognitive function in women with HIV: findings from the Women's Interagency HIV Study. Neurology. 2015;84(3):231-40.

14.• Maki PM, Rubin LH, Springer G, Seaberg EC, Sacktor N, Miller $\mathrm{EN}$, et al. Differences in cognitive function between women and men with HIV. J Acquir Immune Defic Syndr. 2018;79(1):101-7. One of two studies conducted to date that were adequately powered to examine sex differences in neurocognitive function in HIV.

15. Rubin LH, Springer G, Martin EM, Seaberg EC, Sacktor NC, Levine A, et al. Elevated depressive symptoms are a stronger predictor of executive dysfunction in HIV-infected women than men. J Acquir Immune Defic Syndr. 2019;81(3):274-83.

16. Do TC, Kerr SJ, Avihingsanon A, Suksawek S, Klungkang S, Channgam T, et al. HIV-associated cognitive performance and psychomotor impairment in a Thai cohort on long-term cART. J Virus Erad. 2018;4(1):41-7.

17. Gascon MRP, Vidal JE, Mazzaro YM, Smid J, Marcusso RMN, Capitao CG, et al. Neuropsychological assessment of 412 HIVinfected individuals in Sao Paulo, Brazil. AIDS Patient Care STDs. 2018;32(1):1-8.

18.• Sundermann EE, Heaton RK, Pasipanodya E, Moore RC, Paolillo EW, Rubin LH, et al. Sex differences in HIV-associated cognitive impairment. AIDS. 2018;32(18):2719-26. One of two studies conducted to date that were adequately powered to examine sex differences in neurocognitive function in HIV.

19. Heaton RK, Franklin DR Jr, Deutsch R, Letendre S, Ellis RJ, Casaletto K, et al. Neurocognitive change in the era of HIV combination antiretroviral therapy: the longitudinal CHARTER study. Clin Infect Dis. 2015;60(3):473-80.

20. Kabuba N, Menon JA, Franklin DR Jr, Heaton RK, Hestad KA. HIV- and AIDS-associated neurocognitive functioning in Zambia - a perspective based on differences between the genders. Neuropsychiatr Dis Treat. 2016;12:2021-8.

21. Burlacu R, Umlauf A, Luca A, Gianella S, Radoi R, Ruta SM, et al. Sex-based differences in neurocognitive functioning in HIVinfected young adults. AIDS. 2018;32(2):217-25.

22. Foca E, Magro P, Motta D, Compostella S, Casari S, Bonito A, et al. Screening for neurocognitive impairment in HIV-infected 
individuals at first contact after HIV diagnosis: the experience of a large clinical center in Northern Italy. Int J Mol Sci. 2016;17(4): 434.

23. Vassallo M, Durant J, Lebrun-Frenay C, Fabre R, Ticchioni M, Andersen S, et al. Virologically suppressed patients with asymptomatic and symptomatic HIV-associated neurocognitive disorders do not display the same pattern of immune activation. HIV Med. 2015;16(7):431-40.

24. Royal W 3rd, Cherner M, Burdo TH, Umlauf A, Letendre SL, Jumare J, et al. Associations between cognition, gender and monocyte activation among HIV infected individuals in Nigeria. PLoS One. 2016;11(2):e0147182.

25. Behrman-Lay AM, Paul RH, Heaps-Woodruff J, Baker LM, Usher C, Ances BM. Human immunodeficiency virus has similar effects on brain volumetrics and cognition in males and females. J Neuro-Oncol. 2016;22(1):93-103.

26. Basso MR, Bornstein RA. Estimated premorbid intelligence mediates neurobehavioral change in individuals infected with HIV across 12 months. J Clin Exp Neuropsychol. 2000;22(2):208-18.

27. Farinpour R, Miller EN, Satz P, Selnes OA, Cohen BA, Becker JT, et al. Psychosocial risk factors of HIV morbidity and mortality: findings from the Multicenter AIDS Cohort Study (MACS). J Clin Exp Neuropsychol. 2003;25(5):654-70.

28. Tsai AC, Burns BF. Syndemics of psychosocial problems and HIV risk: a systematic review of empirical tests of the disease interaction concept. Soc Sci Med. 2015;139:26-35.

29. Singer M. AIDS and the health crisis of the U.S. urban poor; the perspective of critical medical anthropology. Soc Sci Med. 1994;39(7):931-48.

30. Stern Y. What is cognitive reserve? Theory and research application of the reserve concept. J Int Neuropsychol Soc. 2002;8(3): 448-60.

31. Stern Y, Gurland B, Tatemichi TK, Tang MX, Wilder D, Mayeux $\mathrm{R}$. Influence of education and occupation on the incidence of Alzheimer's disease. JAMA. 1994;271(13):1004-10.

32. Manly JJ, Touradji P, Tang MX, Stern Y. Literacy and memory decline among ethnically diverse elders. J Clin Exp Neuropsychol. 2003;25(5):680-90.

33. Baker DW, Parker RM, Williams MV, Clark WS. Health literacy and the risk of hospital admission. J Gen Intern Med. 1998;13(12): 791-8.

34. Rubin LH, Pyra M, Cook JA, Weber KM, Cohen MH, Martin E, et al. Post-traumatic stress is associated with verbal learning, memory, and psychomotor speed in HIV-infected and HIV-uninfected women. J Neuro-Oncol. 2016;22(2):159-69.

35. Rubin LH, Cook JA, Weber KM, Cohen MH, Martin E, Valcour $\mathrm{V}$, et al. The association of perceived stress and verbal memory is greater in HIV-infected versus HIV-uninfected women. J NeuroOncol. 2015;21(4):422-32.

36. Rubin LH, Sundermann EE, Cook JA, Martin EM, Golub ET, Weber KM, et al. Investigation of menopausal stage and symptoms on cognition in human immunodeficiency virus-infected women. Menopause. 2014;21(9).

37. Rubin LH, Cook JA, Springer G, Weber KM, Cohen MH, Martin EM, et al. Perceived and post-traumatic stress are associated with decreased learning, memory, and fluency in HIV-infected women. AIDS. 2017;31(17):2393-1401.

38. Spies G, Fennema-Notestine C, Cherner M, Seedat S. Changes in cognitive function in women with HIV infection and early life stress. AIDS Care. 2017;29(1):14-23.

39. Sherwin BB. Estrogen and cognitive functioning in women: lessons we have learned. Behav Neurosci. 2012;126(1):123-7.

40. Gandhi M, Bacchetti P, Miotti P, Quinn TC, Veronese F, Greenblatt RM. Does patient sex affect human immunodeficiency virus levels? Clin Infect Dis. 2002;35(3):313-22.
41. Meier A, Chang JJ, Chan ES, Pollard RB, Sidhu HK, Kulkarni S, et al. Sex differences in the Toll-like receptor-mediated response of plasmacytoid dendritic cells to HIV-1. Nat Med. 2009;15(8): 955-9.

42. Scully EP. Sex differences in HIV infection. Curr HIV/AIDS Rep. 2018;15(2):136-46. This review discusses multilevel effects of sex on HIV acquisition, pathogenesis, treatment response, and prospects for cure.

43. Scully EP, Gandhi M, Johnston R, Hoh R, Lockhart A, Dobrowolski C, et al. Sex-based differences in human immunodeficiency virus type 1 reservoir activity and residual immune activation. J Infect Dis. 2019;219(7):1084-94. This study illustrates sex-related differences in immune phenotypes and HIV persistence on ART which have significant implications for cure interventions.

44. Das B, Dobrowolski C, Luttge B, Valadkhan S, Chomont N, Johnston R, et al. Estrogen receptor-1 is a key regulator of HIV1 latency that imparts gender-specific restrictions on the latent reservoir. Proc Natl Acad Sci U S A. 2018;115(33):E7795-E804.

45. Szotek EL, Narasipura SD, Al-Harthi L. 17beta-Estradiol inhibits HIV-1 by inducing a complex formation between beta-catenin and estrogen receptor alpha on the HIV promoter to suppress HIV transcription. Virology. 2013;443(2):375-83.

46. Devadas K, Biswas S, Ragupathy V, Lee S, Dayton A, Hewlett I. Modulation of HIV replication in monocyte derived macrophages (MDM) by steroid hormones. PLoS One. 2018;13(1):e0191916.

47. Laan ETM, Prins JM, van Lunsen RHW, Nieuwkerk PT, Nievaard-Boon MAF. Testosterone insufficiency in human immunodeficiency virus-infected women: a cross-sectional study. Sex Med. 2019;7(1):72-9.

48. Gomes AR, Souteiro P, Silva CG, Sousa-Pinto B, Almeida F, Sarmento A, et al. Prevalence of testosterone deficiency in HIVinfected men under antiretroviral therapy. BMC Infect Dis. 2016;16(1):628.

49. Yoshino Y, Koga I, Misu K, Seo K, Kitazawa T, Ota Y. The prevalence of low serum free testosterone and the short-term effect of anti-retroviral therapy in male Japanese treatment-naive HIV patients. J Infect Chemother. 2019;25(4):318-21.

50. Klein SL, Flanagan KL. Sex differences in immune responses. Nat Rev Immunol. 2016;16(10):626-38.

51. Markle JG, Fish EN. SeXX matters in immunity. Trends Immunol. 2014;35(3):97-104.

52. Schmiedel BJ, Singh D, Madrigal A, Valdovino-Gonzalez AG, White BM, Zapardiel-Gonzalo J, et al. Impact of genetic polymorphisms on human immune cell gene expression. Cell. 2018;175(6):1701-15 e16.

53. Farzadegan H, Hoover DR, Astemborski J, Lyles CM, Margolick JB, Markham RB, et al. Sex differences in HIV-1 viral load and progression to AIDS. Lancet. 1998;352(9139):1510-4.

54. Sterling TR, Vlahov D, Astemborski J, Hoover DR, Margolick JB, Quinn TC. Initial plasma HIV-1 RNA levels and progression to AIDS in women and men. N Engl J Med. 2001;344(10):720-5.

55. Griesbeck M, Ziegler S, Laffont S, Smith N, Chauveau L, Tomezsko P, et al. Sex differences in plasmacytoid dendritic cell levels of IRF5 drive higher IFN-alpha production in women. J Immunol. 2015;195(11):5327-36.

56. Mathad JS, Gupte N, Balagopal A, Asmuth D, Hakim J, Santos B, et al. Sex-related differences in inflammatory and immune activation markers before and after combined antiretroviral therapy initiation. J Acquir Immune Defic Syndr. 2016;73(2):123-9.

57. Giorgi JV, Hultin LE, McKeating JA, Johnson TD, Owens B, Jacobson LP, et al. Shorter survival in advanced human immunodeficiency virus type 1 infection is more closely associated with $\mathrm{T}$ lymphocyte activation than with plasma virus burden or virus chemokine coreceptor usage. J Infect Dis. 1999;179(4):859-70. 
58. Meditz AL, Haas MK, Folkvord JM, Melander K, Young R, McCarter M, et al. HLA-DR+ CD38+ CD4+ T lymphocytes have elevated CCR5 expression and produce the majority of R5-tropic HIV-1 RNA in vivo. J Virol. 2011;85(19):10189-200.

59. Ledwaba L, Tavel JA, Khabo P, Maja P, Qin J, Sangweni P, et al. Pre-ART levels of inflammation and coagulation markers are strong predictors of death in a South African cohort with advanced HIV disease. PLoS One. 2012;7(3):e24243.

60. Kuller LH, Tracy R, Belloso W, De Wit S, Drummond F, Lane $\mathrm{HC}$, et al. Inflammatory and coagulation biomarkers and mortality in patients with HIV infection. PLoS Med. 2008;5(10):e203.

61. Sandler NG, Wand H, Roque A, Law M, Nason MC, Nixon DE, et al. Plasma levels of soluble CD14 independently predict mortality in HIV infection. J Infect Dis. 2011;203(6):780-90.

62. Raghavan A, Rimmelin DE, Fitch KV, Zanni MV. Sex differences in select non-communicable HIV-associated comorbidities: exploring the role of systemic immune activation/inflammation. Curr HIV/AIDS Rep. 2017;14(6):220-8.

63. Lipton SA. Requirement for macrophages in neuronal injury induced by HIV envelope protein gp120. Neuroreport. 1992;3(10): 913-5.

64. Ticona E, Bull ME, Soria J, Tapia K, Legard J, Styrchak SM, et al. Biomarkers of inflammation in HIV-infected Peruvian men and women before and during suppressive antiretroviral therapy. AIDS. 2015;29(13):1617-22.

65. Fitch KV, Srinivasa S, Abbara S, Burdo TH, Williams KC, Eneh P, et al. Noncalcified coronary atherosclerotic plaque and immune activation in HIV-infected women. J Infect Dis. 2013;208(11): 1737-46.

66. Martin GE, Gouillou M, Hearps AC, Angelovich TA, Cheng AC, Lynch F, et al. Age-associated changes in monocyte and innate immune activation markers occur more rapidly in HIV infected women. PLoS One. 2013;8(1):e55279.

67. Looby SE, Fitch KV, Srinivasa S, Lo J, Rafferty D, Martin A, et al. Reduced ovarian reserve relates to monocyte activation and subclinical coronary atherosclerotic plaque in women with HIV. AIDS. 2016;30(3):383-93.

68. Hanna DB, Lin J, Post WS, Hodis HN, Xue X, Anastos K, et al. Association of macrophage inflammation biomarkers with progression of subclinical carotid artery atherosclerosis in HIVinfected women and men. J Infect Dis. 2017;215(9):1352-61.

69. Burdo TH, Weiffenbach A, Woods SP, Letendre S, Ellis RJ, Williams KC. Elevated sCD163 in plasma but not cerebrospinal fluid is a marker of neurocognitive impairment in HIV infection. AIDS. 2013;27(9):1387-95.

70. Krebs SJ, Slike BM, Sithinamsuwan P, Allen IE, Chalermchai T, Tipsuk S, et al. Sex differences in soluble markers vary before and after the initiation of antiretroviral therapy in chronically HIV infected individuals. AIDS. 2016;30(10):1533-42.

71. Hagberg L, Cinque P, Gisslen M, Brew BJ, Spudich S, Bestetti A, et al. Cerebrospinal fluid neopterin: an informative biomarker of central nervous system immune activation in HIV-1 infection. AIDS Res Ther. 2010;7:15.

72. Dunbar N, Pemberton L, Perdices M, Brew BJ. Clinical markers of the presence of dementia and neuropsychological impairment in HIV infection. J NeuroAIDS. 1996;1(4):31-48.

73. Magarinos AM, Somoza G, De Nicola AF. Glucocorticoid negative feedback and glucocorticoid receptors after hippocampectomy in rats. Horm Metab Res. 1987;19(3):105-9.

74. Diorio D, Viau V, Meaney MJ. The role of the medial prefrontal cortex (cingulate gyrus) in the regulation of hypothalamicpituitary-adrenal responses to stress. J Neurosci. 1993;13(9): 3839-47.

75. Meaney MJ, Aitken DH. [3H] Dexamethasone binding in rat frontal cortex. Brain Res. 1985;328(1):176-80.
76. McEwen BS, De Kloet ER, Rostene W. Adrenal steroid receptors and actions in the nervous system. Physiol Rev. 1986;66(4):112188.

77. Sanchez MM, Young LJ, Plotsky PM, Insel TR. Distribution of corticosteroid receptors in the rhesus brain: relative absence of glucocorticoid receptors in the hippocampal formation. $\mathrm{J}$ Neurosci. 2000;20(12):4657-68.

78. Alderson AL, Novack TA. Neurophysiological and clinical aspects of glucocorticoids and memory: a review. J Clin Exp Neuropsychol. 2002;24(3):335-55.

79. McEwen BS, Sapolsky RM. Stress and cognitive function. Curr Opin Neurobiol. 1995;5(2):205-16.

80. McEwen BS. Physiology and neurobiology of stress and adaptation: central role of the brain. Physiol Rev. 2007;87(3):873-904.

81. Jacobs S, Moxley K, Womersley JS, Spies G, Hemmings SM, Seedat S. HPA-axis genes as potential risk variants for neurocognitive decline in trauma-exposed, HIV-positive females. Neuropsychiatr Dis Treat. 2018;14:2497-504.

82. Zapanti E, Terzidis K, Chrousos G. Dysfunction of the hypothalamic-pituitary-adrenal axis in HIV infection and disease. Hormones (Athens). 2008;7(3):205-16.

83. Kumar M, Kumar AM, Waldrop D, Antoni MH, Eisdorfer C. HIV-1 infection and its impact on the HPA axis, cytokines, and cognition. Stress. 2003;6(3):167-72.

84. Patterson S, Moran P, Epel E, Sinclair E, Kemeny ME, Deeks SG, et al. Cortisol patterns are associated with T cell activation in HIV. PLoS One. 2013;8(7):e63429.

85. Valdez A, Rubin LH, Neigh GN. Untangling the Gordian knot of HIV, stress, and cognitive impairment. Neurobiol Stress. 2016;4: 44-54.

86. Raffi F, Brisseau JM, Planchon B, Remi JP, Barrier JH, Grolleau JY. Endocrine function in $98 \mathrm{HIV}$-infected patients: a prospective study. AIDS. 1991;5(6):729-33.

87. Hilton CW, Harrington PT, Prasad C, Svec F. Adrenal insufficiency in the acquired immunodeficiency syndrome. South Med J. 1988;81(12):1493-5.

88. Biglino A, Limone P, Forno B, Pollono A, Cariti G, Molinatti GM, et al. Altered adrenocorticotropin and cortisol response to corticotropin-releasing hormone in HIV-1 infection. Eur J Endocrinol. 1995;133(2):173-9.

89. Verges B, Chavanet P, Desgres J, Vaillant G, Waldner A, Brun JM, et al. Adrenal function in HIV infected patients. Acta Endocrinol. 1989;121(5):633-7.

90. Enwonwu CO, Meeks VI, Sawiris PG. Elevated cortisol levels in whole saliva in HIV infected individuals. Eur J Oral Sci. 1996;104(3):322-4.

91. Lortholary O, Christeff N, Casassus P, Thobie N, Veyssier P, Trogoff B, et al. Hypothalamo-pituitary-adrenal function in human immunodeficiency virus-infected men. J Clin Endocrinol Metab. 1996;81(2):791-6.

92. Christeff N, Gherbi N, Mammes O, Dalle MT, Gharakhanian S, Lortholary O, et al. Serum cortisol and DHEA concentrations during HIV infection. Psychoneuroendocrinology. 1997;22(Suppl 1):S11-8.

93. Chittiprol S, Kumar AM, Shetty KT, Kumar HR, Satishchandra P, Rao RS, et al. HIV-1 clade C infection and progressive disruption in the relationship between cortisol, DHEAS and CD4 cell numbers: a two-year follow-up study. Clin Chim Acta. 2009;409(1-2): 4-10.

94. Kumar M, Kumar AM, Morgan R, Szapocznik J, Eisdorfer C. Abnormal pituitary-adrenocortical response in early HIV-1 infection. J Acquir Immune Defic Syndr. 1993;6(1):61-5.

95. Rondanelli M, Solerte SB, Fioravanti M, Scevola D, Locatelli M, Minoli L, et al. Circadian secretory pattern of growth hormone, insulin-like growth factor type I, cortisol, adrenocorticotropic 
hormone, thyroid-stimulating hormone, and prolactin during HIV infection. AIDS Res Hum Retrovir. 1997;13(14):1243-9.

96. Kajantie E, Phillips DI. The effects of sex and hormonal status on the physiological response to acute psychosocial stress. Psychoneuroendocrinology. 2006;31(2):151-78.

97. Kudielka BM, Kirschbaum C. Sex differences in HPA axis responses to stress: a review. Biol Psychol. 2005;69(1):113-32.

98. Seeman TE, McEwen BS, Singer BH, Albert MS, Rowe JW. Increase in urinary cortisol excretion and memory declines: MacArthur studies of successful aging. J Clin Endocrinol Metab. 1997;82(8):2458-65.

99. McCormick CM, Lewis E, Somley B, Kahan TA. Individual differences in cortisol levels and performance on a test of executive function in men and women. Physiol Behav. 2007;91(1):87-94.

100. Rubin LH, Phan KL, Keating SM, Maki PM. A single low-dose of hydrocortisone enhances cognitive functioning in HIV-infected women. AIDS. 2018;32(14):1983-93.
101. Rubin LH, Phan KL, Keating SM, Weber KM, Maki PM. Brief report: low-dose hydrocortisone has acute enhancing effects on verbal learning in HIV-infected men. J Acquir Immune Defic Syndr. 2017;75(3):e65-70.

102. Hantsoo L, Kornfield S, Iannelli C, Podcasy J, Metzger D, Sammel MD, Epperson CN Glucocorticoid-immune response to acute stress in women and men living with HIV. J Behav Med 2019.

103. Bekhbat M, Mehta CC, Kelly SD, Vester A, Ofotokun I, Felger J, et al. HIV and symptoms of depression are independently associated with impaired glucocorticoid signaling. Psychoneuroendocrinology. 2018;96:118-25.

Publisher's Note Springer Nature remains neutral with regard to jurisdictional claims in published maps and institutional affiliations. 